\title{
Externalizing Behavior Problems in Preschoolers: Impact of an Inhibition Training
}

\section{Alexandra MS Volckaert* and Marie-Pascale Noël}

Universite Catholique de Louvain, Louvain-la-Neuve, Belgium

\begin{abstract}
Background and objective: Externalizing behavior problems are a major cause of consultation in preschoolers but interventions available at this young age are scarce. Recently, researchers developed inhibition training and showed a significant improvement of executive function capacities in typically developing preschoolers and also a positive impact on externalizing behavior problems. In this research, we wanted to replicate this study in a clinical population.

Methodology: Thirty-four preschoolers presenting a high level of externalizing behavior problems took part in an assessment of executive function capacities and behavior, before and after a 8 week period during which half of the children received an inhibition training also involving metacognition (two 45-min sessions per week) while the others (matched on gender and age) were put on a waiting-list.

Results and conclusion: Globally, the intervention lead to significant externalizing behavior problems improvement observed both on parental ratings and in an observational paradigm. As regards inhibition capacities, children who started the intervention with a lower level of inhibition benefitted the most from the intervention. Although increase in executive functions was mainly observed in typically developing children, larger behavioral improvements were observed in the externalizing behavior problems population.
\end{abstract}

Keywords: Inhibition training; Executive function; Externalizing behavior disorders; Preschoolers; Metacognition

\section{Introduction}

"My child is so difficult", "we are exhausted", "we do not know what to do anymore" are all phrases that clinicians hear [1] when parents consult them about the externalizing behavior problems of their child. Externalizing behavior problems (EB) include behaviors as such as physical aggression (e.g. hitting, biting, shoving others), verbal aggression (e.g. teasing, threats) or disruptive behavior (e.g. tantrums, disobedience, agitation, inattention, failure to comply with limits). These behaviors are characterized as "externalized", referring to the fact that they are concrete behaviors directed towards others, as opposed to "internalizing behavior problems" referring to negative emotions directed towards oneself, like anxiety, depression, etc. [2]. Diagnoses of behavior disorders such as ADHD are generally not made before the age of 6, according to DSM-V (Diagnostic and Statistical Manual of Mental Disorders; [3]). However, it is clear that children who are diagnosed after this age often in fact already had difficulties before this. EB may be present in 25 to $40 \%$ of preschool children, including 7 to $15 \%$ with moderate to severe presentation [4,5], but it is not easy to determine in preschoolers whether these behaviors should be considered as pathological or as a part of normal child development. Indeed, a certain level of EB can be considered typical in young children [6], as EB problems lie on a continuum from normal to pathological. Although, in some cases, symptoms of EB improve, or even disappear [7], the opposite is also observed and is more problematic. Indeed, EB can persist over time into adolescence for some [8-10], but also into adulthood [11]. This persistence of EB can therefore lead to difficulties in terms of social inclusion [12] as well as in terms of academic performance $[13,14]$. It is thus important to diagnose and to offer therapeutic programs for these EB problems in very young children.

Researchers have highlighted various risk factors that play a role in the emergence of EB at preschool age. These include environmental, family and child risk factors. For example, factors such as poverty, social isolation and structural characteristics of the family have been examined [15]. At the family level, an insecure or disorganized attachment and negative control in parenting (hard and inconsistent punishment, high coercion, etc.) have been considered as contributors to EB [16]. Authors have also shown that household chaos seems to be associated with negative outcomes in preschoolers such as hardto-manage temperament, aggression, conduct problems or even hyperactivity $[17,18]$. At the child level, risk factors such as peer rejection, gender (being a boy), temperament (e.g. low self-control), and medical problems during childhood or even cognitive abilities also seem to be related to EB $[15,16,19]$. Moreover, we need to point out the cumulative effect of risk factors: the greater the number of risk factors, the greater the likelihood of developing EB [15,16].

Concerning the role of cognitive abilities, there is a growing literature over the last two decades which shows a significant association between poor executive functions (EF) and EB in both typically developing (TD) and EB preschooler populations. Moreover, researchers highlight, in TD children, that a measurement of EF at preschool age could predict EB one year later [20], two years later [21] or even up to three years later [22]. It seems, however, that inhibition capacities are the EF most strongly associated with $\mathrm{EB}$, with a generally higher error rate in inhibition tasks in EB populations than in community samples [23-30].

Recently, two meta-analyses were conducted on the association between EB and EF in pre-schoolers. In the first, Pauli-Pott and Becker [31] observed a high correlation between ADHD symptoms and attention-vigilance measures $(r=0.27)$, interference control $(r=0.26$,

*Corresponding author: Alexandra MS Volckaert, Universite Catholique de Louvain, Louvain-la-Neuve, Belgium, Tel: +32 478700 701; E-mail: alexandra.volckaert@uclouvain.be

Received June 01, 2016; Accepted September 06, 2016; Published September 13, 2016

Citation: Volckaert AMS, Noël MP (2016) Externalizing Behavior Problems in Preschoolers: Impact of an Inhibition Training. J Psychol Abnorm 5: 154. doi: 10.4172/2471-9900.1000154

Copyright: (C) 2016 Volckaert AMS, et al. This is an open-access article distributed under the terms of the Creative Commons Attribution License, which permits unrestricted use, distribution, and reproduction in any medium, provided the original author and source are credited. 
e.g. Stroop test) and inhibition ( $r=0.29$, e.g. in a Go-NoGo task). However, they found only a weak correlation with flexibility and working memory measures. The second meta-analysis was conducted by Schoemaker et al. [32] with EB pre-schoolers as well as with children presenting oppositional defiant disorder. Their results point in the same direction as those of the first authors: EB is related to an overall EF factor $(r=0.22)$ and more specifically to inhibition $(r=0.24)$. Effect sizes are indeed smaller for working memory $(r=0.17)$ and flexibility $(r=0.13)$. Unlike Pauli-Pott and Becker [31], Schoemaker et al. [32] did not explore the link with attention capacities.

A few studies have tried to manipulate the EF capacities of children by implementing training programs. These showed that it is possible to enhance overall EF in pre-schoolers [33] and more specifically to improve inhibition [34-36] and working memory [36,37]. Yet, to our knowledge, only two studies have measured the impact of an EF training program on EB problems in pre-schoolers. First, Tamm et al. [38] developed a 8 week training program focusing on several cognitive functions (attention, memory, inhibition, hand-eye coordination, etc.) and metacognition. Twenty-four preschoolers presenting ADHD symptoms and their parents attended eight $60 \mathrm{~min}$ sessions during which the children performed exercises/games focusing on these cognitive functions and the parents were taught how to be behavioral interventionists at home. Analyses of the cognitive outcomes indicated an improvement on attention and working memory, but not on inhibition. Concerning behavioral measures, both parents and clinician rated children as being more attentive, but no improvements were measured on symptoms of hyperactivity or impulsivity or on ADHD behaviors in the classroom. This study was the first one to measure the impact of an EF training program on EB in preschoolers. However, several caveats prevent us from drawing any clear conclusion about the causal link between EB and EF based on these data. First of all, the training program concerns several cognitive functions and is not restricted to EF. Second, concurrent to this cognitive training of children, parents were also given guidelines how to implement the exercises at home and principles of behavior modification techniques, so that we cannot determine which of the interventions had the biggest impact. Finally, there was no control group in this study to ensure that the observed improvements could not be imputed to the spontaneous cognitive growth of the child or to the simple fact of the parents and the child receiving attention and support from the therapists.

More recently, Volckaert and Noël [39] showed, in 47 typically developing (TD) preschoolers, that a cognitive intervention aiming at enhancing inhibition capacities had an impact not only on executive functions but also on behavior, with a decrease in EB problems. The intervention consisted of $45 \mathrm{~min}$ sessions, twice a week, for 8 weeks. The interventionists focused on exercises/games which targeted inhibition exclusively but also used metacognition. A control group received a series of handicraft sessions (same number of sessions and same duration of the experimental group). Only children participated; parents were not involved in the sessions and did not know which condition their child was in. The authors observed significant differences between the control and the experimental groups, with better performances for the experimental group on inhibition, attention and working memory measures. More importantly, differences were also observed on behavioral measures of inattention and on negative reactions in an observational paradigm. Volckaert and Noël [39] thus highlighted that it is possible to improve EF capacities during the preschool period and that this has an impact on EB. However, they worked with TD children. To our knowledge, no study had yet tested this kind of intervention in EB preschoolers.
In this present study, we wanted to know whether the intervention developed by Volckaert and Noël [39] would lead to the same beneficial effects for children who present EB problems. To that end, we implemented the same inhibition training on a group of children with EB problems and compared their development to that of another group of children with EB problems who were on a waiting list. Two opposite predictions were considered. On the one hand, we might predict that children with EB would largely benefit from the intervention, leading to both an enhancement of their EF functions and a decrease of their EB problems. Indeed, children with EB problems are characterized by poor EF and Volckaert and Noël [39] observed that children with a low inhibition level in pretest were the ones who benefited the most from the intervention. On the other hand, preschoolers with EB have multiple risk factors $[15,16]$ and it is possible that focusing on a single factor is insufficient to induce any significant improvement. To answer this question, we will compare the change in both $\mathrm{EF}$ capacities and $\mathrm{EB}$ problems of the EB children in the training condition to those from the waiting list. We will discuss our results, compared to those of Volckaert and Noël [39].

\section{Materials and Methods}

\section{Participants}

Thirty-four children (22 boys, 12 girls) with EB problems were recruited in the French part of Belgium. We broadcast the announcement of our research among pediatricians, schools and the media. Interested parents registered online and were asked to complete the Child Behavior Checklist [CBCL; 40]. As 21 is the cut-off score on this scale above which a child is considered to actually present $\mathrm{EB}$, only children with a score of 21 or above were selected for the study. Children were between $3: 3$ and $6: 2$ years old ( $M$ age $=4: 6$ years, $\mathrm{SD}=10$ months). Parental level of education was evaluated using a seven-point scale from low (incomplete elementary school) to high (university) education. Mean level of education was $5.42(\mathrm{SD}=1.46)$ for the mothers and $5.03(\mathrm{SD}=1.52)$ for the fathers, which corresponds to short higher education. Monthly income (including any source of net income, for both parents), was rated using a nine-point scale from low (0-500 euros) to high income (more than 4000 euros). Mean was 7.27 ( $\mathrm{SD}=2.04)$, which corresponds to an income of 3000-3500 euros a month.

\section{Procedure}

Among the 34 children, 17 were allocated to the control group, which was a waiting-list, and the other 17 children, matched on gender and age to the control group's children, were allocated to the experimental condition. All children took part in a pre-test involving a short assessment of IQ, executive functions and behavior. The total testing duration was approximately 60-75 min per child, so we saw each child twice, for an individual testing. We were careful to alternate between verbal and non-verbal tasks. Children from the waiting-list group stayed at home for 8 weeks while children from the intervention group were invited to participate in 2 weekly training sessions of $45 \mathrm{~min}$ for 8 weeks. At the end of this 8 week period of waiting or receiving intervention, every child took part in the post-test (same baseline as in pretest, except for IQ). All sessions (testing and intervention) took place in offices of the university. Finally, in order to examine whether the possible positive impact on behavior was stable, we asked parents to complete the behavioral questionnaire again 4 months after the end of the intervention.

\section{Instruments}

Instruments for the inclusion criteria: Child behavior checklist: We asked parents to fill in the Child Behavior Checklist [CBCL; 40] in 
order to be sure the children actually presented EB. This questionnaire is constituted by a list of statements about the child's everyday life behaviour to rate on a Likert scale ranging from "not applicable" (0) to "applies more or less or sometimes" (1) to "always applicable" (2). The EB scale is the sum of the "Aggressive Behavior" subscale which is constituted by 19 items and the "Attention Problems" subscale which is constituted by 5 items. The "anxiety/depression" scale ( 8 items) was also taken into account as a measure of internalized problems. CBCL scales have a Cronbach's alpha between 0.63 and 0.86 and test-retest reliability is 0.85 [40]. The parents filled in this questionnaire again in post-test.

Wechsler preschool and primary scale of intelligence: We used two subscales of the Wechsler Preschool and Primary Scale of Intelligence [WPPSI-III; 41] in pretest to exclude possible mental retardation. These two subscales were "Information" from the verbal scale and "Block design" from the performance scale. Standard scores for these subtests have a mean of $10 \pm 3$. A global score was calculated as the mean of the two standard scores. To take part in the study, children had to be in the normal range $( \pm 1.5 \mathrm{SD})$, i.e., to have a global score lying between 5.5 and 14.5 .

Behavioral measures: EB was measured with questionnaires filled in by parents and teachers as well as with an observational paradigm.

Conners rating scale: We asked parents and teachers to fill in the Conners Parent and Teacher Rating Scale [CPRS, CTRS; 42] for each child tested. These questionnaires, measuring parents' and teachers' perception of child hyperactivity, inattention, impulsivity and conduct disorders, are composed of 48 items in the parent version and 28 items in the teacher version. Adults must choose whether the statement represents a common behavior of the child (four-point Likert scale from "not at all" to "very much"). Inattention, hyperactivity/impulsivity and conduct disorder factors were used in this study and were calculated as the sum of the respondents' ratings of the relevant observed behaviors. T-scores (mean of 50, SD of 10) are then calculated and taken into account in our analysis. The factorial structure of the parent version was validated recently by Catale, Geurten, Lejeune and Meulemans [43]. Good psychometric qualities were confirmed, as Cronbach alpha was between 0.76 and 0.80 for the three main scales (conduct problems, learning difficulties and impulsivity/hyperactivity).

Unfair card game: The Unfair Card Game [44] is inspired by an adult paradigm focusing on perspective-taking [45] and is based on a cooperative computer game where the child is invited to play with a virtual child named Thomas. It has been designed to induce spontaneous positive affects in the first part and frustration in the second part. The game is presented to the child as a game where he/she can win candy. The child sits at a table facing the computer, next to the examiner. When the game starts, instructions are given to the child by a virtual examiner (a previously video-recorded adult). Two cards are shown on the screen; on one of them there is a picture of a piece of candy. Then the cards turn over and start to move. When the cards stop moving, the child must indicate which the card with the candy is. The child is invited to play five rounds. For each correct answer, he/she gives a piece of candy to Thomas, his virtual partner. After the first five rounds, it's time for Thomas to play. It is explained that a piece of candy will be given to the child for each of Thomas's correct responses. However, the game is rigged such that the child wins his/her five rounds and therefore Thomas wins five pieces of candy (this is called the winning phase), but Thomas wins only one round, so the child receives only one piece of candy (losing phase). At the end of the game, Thomas tells the child that he played badly and that he will therefore share his candies with the child. In this way, the level of frustration of the child returns to normal. This game lasts for $10 \mathrm{~min}$. The advantage of this observational paradigm is that we can control the reaction of the adversary, as each child is faced with the same virtual partner (Thomas). The speech of the examiner is also strictly standardized (comments made at the end of each round, for the two phases). The UCG is video-recorded and coded following standardized guidelines. Four dimensions are coded: positive affect (smile, laughter, etc.) negative affect (tears, insults, etc), agitation (movements) and inattention (distraction). For each of these dimensions, the frequency and the intensity is taken into account when coding, using a 5-point Likert scale ranging from 1 (neither frequent nor intense) to 5 (very frequent and intense). Coding was done by trained coders. The intercoders' reliability, calculated with the weighted Kappa coefficient, reaches 0.766 .

Cognitive measures: Verbal and motor inhibition, flexibility, memory and visual and auditory attention were assessed.

\section{Verbal inhibition}

Cat-dog-fish: The cat-dog-fish task [46] is a task inspired by the Day/Night test [47] which assesses inhibitory control. There are two conditions: in the control condition, a card of 24 drawings (cats, dogs and fish) is presented to the child. $\mathrm{He} /$ she must name the pictures on the card as quickly as possible and without error. In the inhibition condition, we tell the child that, on Mars, "cats" are called "dogs", "dogs" are called "cats" and fishes are called fishes (in French, the word for "cat" (chat) is very close phonologically to the word "dog" (chien)). The child is invited to follow the new rule and give the "Martian" animal names for the animals on the second card as fast as possible and without error. The reliability of this test measured by Cronbach's alpha is excellent for the inhibition condition (0.92) [39]. The number of correct responses is scored.

Vegetable stroop: This task also assesses verbal inhibition [48]. It is composed of 3 cards in A4 format. In the first control condition (naming), 5 rows of 9 colored squares (red, green or orange) are presented to the child. The child has to name, as quickly as possible and without making any error, the color of the squares. In the second condition, 5 rows of 9 vegetables are presented in prototypic colors (tomato, salad, carrot) and the child has to denominate, as quickly as possible and without making any error, the color of the vegetable. In the third condition, the vegetables are no longer in prototypic colors. Tomatoes are drawn in blue, salad in yellow and carrots in brown. The child must not name the color in which the vegetables are shown but the color of the vegetable "in real life". In the last condition, the vegetables are still not drawn in prototypic colors, but this time the color of the drawing interferes with the color of other vegetables. Again, the child has to name the color of the vegetables "in real life" and inhibit the color of the drawing. Each part was preceded by 8 practice items. Reaction time and errors for each part are taken into account.

\section{Motor inhibition and flexibility}

Knock and tap: The Knock and Tap task from the NEPSY battery [49] is used to assess motor inhibition. There are two parts: in the first part, child is asked to knock on the table when the examiner taps, and vice versa; in the second part, when the examiner taps with the side of the fist, the child must knock with the knuckles (and vice versa), but when the examiner taps with the palm the child must do nothing. The total score for the two parts is the number of correct responses ( 30 maximum).

Head-toes-knees-shoulders: This task was developed by Ponitz et al. [50]. It was originally composed of three parts, but we added a fourth 
one. In the first part, the child is asked to touch his/her head when the examiner says "touch your feet", and to touch his/her feet when the examiner says "touch your head". In the second part, shoulders and knees are added. The child must now touch his/her knees when the examiner says "touch your shoulders" and vice versa, in addition to the two instructions in Part 1. In the third part, the rules are changed: the child must now touch his/her knees when the examiner says "touch your head" and touch his/her shoulders when he says "touch your feet" (and vice versa). This third part is administered only if the child has correctly answered at least 5 of the 10 items in Part 2 . We created a fourth part, which is always performed, in order to test flexibility. In this part, there are two hoops on the floor, a red one and a blue one. When the examiner is in the blue hoop, the child has to do what the examiner says (i.e., to touch his/her head when the examiner says "touch your head" and to touch his/her feet when told to do so). However, when the examiner is located in the red hoop, the child must do the opposite and touch his/her feet when told to touch his/her head (and vice versa). At the beginning of each part, there are 8 practice items to ensure that the child understands the rule. The number of correct responses for each part is calculated. For inhibition, we used the number of correct responses for the first three parts. For flexibility, we used the number of correct responses for part 4 .

Visual attention: The cats task from the NEPSY battery [49] is a cancellation task measuring selective visual attention. The child had to cancel as many cats as possible without paying attention to distractors. Maximum duration is 180 seconds. The child is asked to be as fast as possible. The internal consistency is good $(0.71)$ and the test-retest stability correlation is 0.62 . Our measure is the precision (number of correct responses minus errors).

Auditory attention: In this task from the NEPSY battery [49], the child listens to an audio recording and has to put a red square in a box when and only when he/she hears the word "red". The internal consistency is good (0.81) and the test-retest stability correlation is 0.81 . Precision score used in this study is calculated by subtracting errors from correct responses.

\section{Working memory}

Word span: The Word Span task [51] was used to assess verbal short-term memory (phonological loop). In this task, the examiner presents a series of words to the child (one per second), who is asked to repeat them in the same order. The first level of difficulty includes two words, and one more word is added for each new level. Each level of difficulty has three trials, and if the child fails at least two out of the three trials, then the task is stopped. We used the corrected span as the dependent measure: this is the longest sequence for which two series were repeated correctly, plus .5 if one longer series was also correctly processed.

Block tapping test: The Block Tapping Test [51], initially developed by Corsi [52], is a measure of short-term memory of visuospatial information (visuospatial sketchpad). The examiner and the child sit face to face with a board between them, onto which are glued nine identical cubes. The child has to imitate the path of the examiner, who touches sets of cubes of increasing number. There are, as for the word span task, three trials per level. We again used the corrected span as the dependent measure.

Categospan: This complex span task [51] was used to assess the central executive. The examiner orally presents one-syllable food or animal words which the child must then repeat by category, first naming the food items, then the animals. Trials with items drawn on cards are performed first to ensure that the child understands the instructions, and pictures of a forest and a plate are presented to the child to help recall animal and food names, respectively. There were three trials per level, with trial set length increasing in each level. We used the corrected span as the dependent measure.

\section{Executive function questionnaire}

Childhood executive functioning inventory: We asked parents and teachers to fill out the French version of the Childhood Executive Functioning Inventory [CHEXI; 53], which evaluates the executive functioning of the child. It is composed of 24 items focusing on two factors, inhibition and working memory and scored on 1-to-5-point Likert-type scales. A mean score is calculated for each factor. This French version presents a good internal consistency (Cronbach's alpha was 0.85 for the inhibition subscale and .89 for the working memory subscale) and high test-retest reliability for the two subscales was also established $(0.87$ for the inhibition subscale and 0.75 for the working memory subscale).

Inhibition training: In this study, we used the training program of Volckaert and Noël [39]. Intervention was held in small groups of three or four children. Each session was led by an experienced neuropsychologist (the first author of this paper). The training consisted in exercises/games tapping on the four components of inhibition functions: interruption of an ongoing response, impulsivity control, inhibition of a predominant response and inhibition of external distractors. Particular emphasis was placed on the proximal zone of development: games were not too easy to avoid boredom in the children, nor too difficult, to avoid discouragement or dropping out. Before starting each new game, the interventionist ensured that all children in the group had understood the rules. Some of the games were for the whole group; some others were for pairs (e.g. day/night exercises). The complete description of the training sessions can be found in Volckaert and Noël [39].

One particularity of this intervention is the use of fictional characters in order to improve the metacognition of executive functions in children. These characters were inspired by Reflecto [54], an intervention method using metacognition by introducing eight characters, each one with a different job representing one of the EF. The use of the jobs metaphor allows activation, in a single image, of a set of mental representations already present in the child's repertoire. In our intervention, we used three characters (as in Volckaert and Noël [39]): the policeman, the statue and the detective. The policeman blows in his whistle and waves "stop" with his hand. This character is used whenever the exercise involved inhibition of a predominant response. Children also learn a little song associated with this character: "Stop: first I think and then I do." It helped children not to go too fast or too impulsively. Second, the statue was used in exercises requiring motor control and calm, forcing children to pay attention to the body parts which have most tendencies to move and to learn to control these parts. Finally, the detective helped children to check whether they had made any errors in the game or to check the performance of others. Thanks to these characters, children learned which function was most involved in which games. Although the sessions were led in groups, every child was always in action, even if it was not his/her turn to answer, as he/she also had to check the others' responses for mistakes. Feedback was given to the children continuously during the games using these characters. For example, in a game focusing on the control of a dominant response, children received a "policeman card" each time they answered correctly. By contrast, if a child gave an answer when it was not his/her turn, or he/she did not interrupt an ongoing response, the person leading the 
training session notified the child verbally, and the child lost one of his/ her policeman cards. Sessions were held in small groups, as children can benefit from the help of their peers in these kinds of training sessions. The intervention comprised 16 sessions of $45 \mathrm{~min}$ : twice a week for 8 weeks. Children from the waiting list were just seen for the pretest and for the posttest 8 weeks later.

\section{Results}

\section{Data analysis}

Only 14 teachers filled in the questionnaires in both pre- and post-test. Indeed, some have not agreed to participate in the study, some were not aware of the participation of their pupil in the study, by parental choice, and others only filled in the questionnaires in pretest. This very small return rate (14 out of 34 ) prevented any valuable analyses from being done.

Since there exists no pure measure of EF (as it always involves something else like naming, motor response, color detection, etc.), we calculated factors that accounted for the common variance of the different tasks touching on each specific executive function. We tested whether the intervention and the waiting-list groups were equivalent in the pretest. Then, we calculated repeated measures ANOVAs with Time (pre- and post-test) as the within-subject factor and Group (intervention and waiting-list) as the between-subjects factor, on each of these factors as the dependent measure, as well as on the behavioral measures. When a significant time-by-group interaction emerged, paired-samples $t$-tests were calculated separately on each group to measure the improvement from pre- to post-test. Effect sizes were calculated using partial eta square $\left(\eta_{\mathrm{p}}{ }^{2}\right)$. The level of significance for all tests was set at 0.05 .

\section{Factorial analyses $^{1}$}

We used factorial analyses in principal components forced to one factor to aggregate tasks from the pretest measuring the same function. A factor was calculated on tasks measuring inhibition (number of correct responses for Knock and Tap, and for the inhibition parts of Cat-Dog-Fish, Vegetable Stroop (last two inhibition parts) and HTKS (sum of the first three inhibition parts)). The saturation of tasks on this Factor ranged from 0.670 to 0.855 , and it accounted for $58.95 \%$ of the variance. A second factor was calculated on the tasks measuring attention (precision ${ }^{2}$ for Cats and Auditory Attention). The saturation of each task was 0.861 and it accounted for $74.18 \%$ of the variance. The third factor was calculated on tasks measuring working memory (span for Categospan, Word span and Block Tapping Test). It explained $73.43 \%$ of the variance, and the saturations ranged from 0.790 to 0.902 . Table 1 shows the loadings of each task into factor. As often reported in the literature [55-57], we observe good correlations between the factors (see Table 2). On the basis of the loading found in those analyses, we calculated a factorial score for each factor at pretest and post-test.

\section{Between group comparisons in pre-test}

Testing of the equivalence of the two groups in pretest is reported in Table 3. Groups were equivalent on all demographic variables, on all cognitive measures except attention factor for which the control group showed weaker performance, and on all behavioral measures, except the agitation in UCG where children from the control group were less agitated that those from the intervention group.

${ }^{1}$ We did not consider response time because (1) some tasks were not timed and (2) analyses on response time did not lead to any significant results. It should be mentioned that our intervention was not focused on speed but more on accuracy. ${ }^{2}$ Precision=number of correct response minus errors.

${ }^{3}$ CBCL EB: $t(22)=9.497, p=<0.001$; CBCL Agressive behaviors: $t(22)=9.166$, $p=<0.001$

\section{Effect of the intervention}

Effects of the intervention were assessed by computing repeated measures ANOVA with Time (pre and post-test) as the within-subject factor and Group (intervention and waiting-list) as the betweensubjects factor. We were particularly interested in the Time $\mathrm{x}$ Group interaction as an indicator of a training effect. All results are reported in Table 4.

Inhibition: The ANOVA calculated on the inhibition factor only showed a significant main effect of time $(F(1,29)=22.196, p=<0.001$, $\left.\eta_{\mathrm{p}}{ }^{2}=0.434\right)$. Between pre- and post-test, children improved their performances in those inhibition tasks. To examine whether some of the children's characteristics could account for the differential benefit of the intervention, we split the intervention group in two, according to the level of inhibition measured in the pretest (median split). The repeated measures ANOVA showed again a significant effect of time $\left(F(1,14)=8.328, p=0.012, \eta_{\mathrm{p}}{ }^{2}=0.373\right)$, of inhibition level in pretest $(F$ $\left.(1,14)=11.775, p=0.004, \eta_{\mathrm{p}}{ }^{2}=0.457\right)$ and a significant time-by-inhibitionlevel interaction $\left(F(1,14)=8.911, p=0.010, \eta_{\mathrm{p}}{ }^{2}=0.389\right)$. Indeed, children who started with a low level of inhibition benefited more from the intervention than those who had a higher level of inhibition in pretest (Low level : significant improving mean of $25.98 \pm 19.06, t(7)=-3.855$, $p=0.006$; High level: non-significant improving mean of $-.44 \pm 16.2$, $t(7)=0.077, p=0.941)$ (see Figure 1). It is however important to note that high-level children did not present ceiling effect in pretest and had thus the possibility to improve their inhibition capacities.

Attention: The repeated measures ANOVA calculated on the attention factor showed a significant effect of time $(F(1,30)=10.398$, $\left.p=0.003, \eta_{\mathrm{p}}^{2}=0.257\right)$ and a significant time-by-group interaction $(F$ $\left.(1,30)=17.447, p=<0.001, \eta_{p}{ }^{2}=0.368\right)$ (see Table 4). However, when we ran the Paired-Samples $t$ Test for each group separately, we found, surprisingly, that the waiting-list group improved their attention capacities $(t(15)=-5.151, p<0.001)$, which is not the case for the

\begin{tabular}{|c|c|}
\hline Tasks & Loadings on the factor \\
\hline \multicolumn{2}{|l|}{ Factorial analysis for Inhibition } \\
\hline Knock and Tap & 0.855 \\
\hline HTKS $^{a}$ & 0.839 \\
\hline Vegetable Stroop $\mathrm{CR}^{\mathrm{a}}$ & 0.689 \\
\hline Cat-dog-Fish CR ${ }^{a}$ & 0.67 \\
\hline$\%$ of explained variance & 58.95 \\
\hline \multicolumn{2}{|l|}{ Factorial analysis for Attention } \\
\hline Cats Precision (CR - Err) & 0.861 \\
\hline Auditory Attention Precision (CR - Err) & 0.861 \\
\hline$\%$ of explained variance & 74.18 \\
\hline \multicolumn{2}{|l|}{ Factorial analysis for Working Memory } \\
\hline Categospan & 0.902 \\
\hline Words span & 0.875 \\
\hline Block Tapping Test & 0.79 \\
\hline$\%$ of explained variance & 73.43 \\
\hline
\end{tabular}

Table 1: Tasks loadings for the factors resulting from the factorial analysis on the data in pre-test and percentage of explained variance.

\begin{tabular}{|c|c|c|c|}
\hline Variable & $\mathbf{1}$ & $\mathbf{2}$ & $\mathbf{3}$ \\
\hline $1 . \quad$ Inhibition Factor & - & $0.499^{* *}$ & $0.736^{\star * *}$ \\
\hline 2. Attention Factor & & - & $0.624^{\star * *}$ \\
\hline 3. Working Memory Factor & & & - \\
\hline${ }^{*} p \leq 0.05,{ }^{* *} p \leq 0.01,{ }^{* * *} p<0.001$ & & & \\
\hline
\end{tabular}

Table 2: Inter correlations among the factors in pretext with chronological age in pretext as covariate variable. 
Citation: Volckaert AMS, Noël MP (2016) Externalizing Behavior Problems in Preschoolers: Impact of an Inhibition Training. J Psychol Abnorm 5: 154. doi: $10.4172 / 2471-9900.1000154$

Page 6 of 11

\begin{tabular}{|c|c|c|c|c|c|c|c|}
\hline & & \multirow[b]{2}{*}{$\mathbf{N}$} & \multirow[b]{2}{*}{$\begin{array}{l}\text { Waiting-list } \\
\text { group }\end{array}$} & \multirow[b]{2}{*}{$\mathbf{N}$} & \multicolumn{2}{|c|}{ Pretest } & \multirow[b]{2}{*}{$d$ Cohen $(r)$} \\
\hline & & & & & Intervention group & $\begin{array}{c}\text { Independent-Samples } \\
t \text { Test }\end{array}$ & \\
\hline Variables & & & $M(\mathrm{SD})$ & & $M(\mathrm{SD})$ & & \\
\hline Demographic & Sex (Male) & 17 & 11 & 17 & 11 & $0.000^{\mathrm{a}}$ & \\
\hline \multirow[t]{5}{*}{ Data } & CA (in months) & 17 & $51.41(10.06)$ & 17 & $56.53(8.98)$ & -1.565 & \\
\hline & $\begin{array}{l}\text { Mean of IQ } \\
\text { subtests }\end{array}$ & 17 & $97.35(22.92)$ & 17 & $99.71(21.61)$ & -0.308 & \\
\hline & $\begin{array}{l}\text { Mother education } \\
\quad(\max =7)\end{array}$ & 17 & $5.47(1.46)$ & 16 & $5.38(1.50)$ & 0.185 & \\
\hline & $\begin{array}{l}\text { Father education } \\
\quad(\max =7)\end{array}$ & 17 & $5.29(1.45)$ & 14 & $4.71(1.59)$ & 1.062 & \\
\hline & $\begin{array}{l}\text { Family income } \\
\quad(\max =9)\end{array}$ & 17 & $7.53(1.77)$ & 16 & $7.00(2.31)$ & 0.742 & \\
\hline Cognitive & Inhibition Factor & 15 & $99.27(21.15)$ & 16 & $108.79(23.54)$ & -1.181 & \\
\hline \multirow[t]{5}{*}{ measures } & Attention Factor & 16 & $25.02(14.36)$ & 16 & $36.11(12.90)$ & $-2.297^{*}$ & $-0.81(-0.38)$ \\
\hline & WM Factor & 17 & $6.43(1.65)$ & 17 & $7.26(1.73)$ & -1.427 & \\
\hline & Flexibility & 17 & $12.12(3.16)$ & 17 & $14.18(4.19)$ & -1.618 & \\
\hline & $\begin{array}{c}\text { CHEXI WM } \\
\text { (parent) }\end{array}$ & 17 & $2.72(.72)$ & 16 & $2.38(0.76)$ & 1.306 & \\
\hline & $\begin{array}{l}\text { CHEXI Inhibition } \\
\text { (parent) }\end{array}$ & 17 & $3.89(0.49)$ & 16 & $3.59(0.77)$ & 1.377 & \\
\hline Behavioral & $\begin{array}{l}\text { UCG positive } \\
\text { affects }\end{array}$ & 16 & $1.25(0.41)$ & 16 & $1.15(0.34)$ & 0.776 & \\
\hline \multirow[t]{10}{*}{ measures } & $\begin{array}{l}\text { UCG negative } \\
\text { affects }\end{array}$ & 16 & $1.58(0.70)$ & 16 & $1.85(0.85)$ & -0.98 & \\
\hline & UCG agitation & 16 & $3.00(1.15)$ & 16 & $4.15(0.70)$ & $-3.410^{* \star}$ & $-1.21(-0.52)$ \\
\hline & UCG inattention & 16 & $2.17(0.88)$ & 16 & $2.06(0.94)$ & 0.323 & \\
\hline & $\begin{array}{l}\text { CPRS conduct } \\
\text { problems }\end{array}$ & 17 & $65.35(11.34)$ & 16 & $61.94(15.87)$ & 0.715 & \\
\hline & $\begin{array}{c}\text { CPRS } \\
\text { hyperactivity }\end{array}$ & 17 & $70.88(11.13)$ & 16 & $67.44(17.33)$ & 0.684 & \\
\hline & CPRS impulsivity & 17 & 65.65 (9.73) & 16 & $63.56(13.67)$ & 0.507 & \\
\hline & CBCL Anx/Dep & 17 & $6.41(4.14)$ & 17 & $5.59(2.92)$ & 0.671 & \\
\hline & CBCL Att Prob & 17 & $4.71(1.93)$ & 17 & $5.00(2.74)$ & -0.362 & \\
\hline & CBCL Agg Behav & 17 & $24.71(4.59)$ & 17 & $23.71(4.77)$ & 0.623 & \\
\hline & CBCL EB & 17 & $29.41(5.80)$ & 17 & $28.71(6.75)$ & 0.327 & \\
\hline
\end{tabular}

Note: $C A=$ Chronological Age; $I Q=I n t e l l e c t u a l$ Quotient; WM=Working memory; CHEXI=Childhood Executive Functioning Inventory; UCG=Unfair Card Game; CPRS=Conners Parent Rating Scale; CBCL Anx/Dep: Anxiety/Depression scale of the CBCL; CBCL Att Prob: Attention problems scale of the CBCL; CBCL Agg Behav: Aggressive Behaviors scale of the CBCL; CBCL EB=Externalized Behaviors scale of the $C B C L{ }^{*} p \leq 0.05,{ }^{* *} p \leq 0.01,{ }^{* * *} p<0.001$; a Analysis= $x^{2}$

Table 3: Mean scores and standard deviations for the waiting-list and intervention groups in pre-test session and between-group comparisons.

intervention group $(t(15)=0.685, p=0.504)$. This improving is in fact due to the auditory attention task more than to the visual attention task. Indeed, a significant effect of time $\left(F(1,30)=6.662, p=0.015, \eta_{\mathrm{p}}{ }^{2}=0.182\right)$ and a significant time-by-group interaction $(F(1,30)=19.780, p<0.001$, $\left.\eta_{\mathrm{p}}{ }^{2}=0.397\right)$ is found for the auditory attention task with children from the waiting-list improving from pre- to post-test $(t(15)=-4.969$, $p<0.001)$, which was not the case of children from the intervention group $(t(15)=1.320, p=0.207)$. However, for the visual attention task, we only observed an effect of time $\left(F(1,32)=17.274, p<0.001, \eta_{p}{ }^{2}=0.365\right)$ showing that both groups improved similarly.

Working memory: The repeated measures ANOVA calculated on the working memory factor showed a significant main effect of time $\left(F(1,32)=13.443, p=0.001, \eta_{\mathrm{p}}{ }^{2}=0.296\right)$ and a significant time-by-group interaction $\left(F(1,32)=6.661, p=0.015, \eta_{p}^{2}=0.172\right)$ (see Table 4). Here again, the waiting-list group improved significantly over time $(t(16)=-$ 4.041, $p=0.001$ ) while this was not the case for the intervention group $(t(16)=-0.855, p=0.405)$.

Flexibility: The same analysis conducted on the flexibility part of HTKS showed only a marginal effect of group $(F(1,32)=3.830, p=0.059$, $\eta_{\mathrm{p}}{ }^{2}=0.107$ ) but no effect of time and no time-by-group interaction (see Table 4).
EF questionnaire (CHEXI): Repeated measures ANOVAs were calculated on the two dimensions of the CHEXI evaluated by the parents, working memory and inhibition. A significant effect of time was observed for working memory $\left(F(1,31)=5.480, p=0.026, \eta_{p}^{2}=0.150\right)$. For both dimensions, we observed a marginal effect of group (working memory: $F(1,31)=3.306, p=0.079, \eta_{\mathrm{p}}{ }^{2}=0.096$; inhibition: $F(1,31)=4.080, p=0.052$, $\left.\eta_{\mathrm{p}}{ }^{2}=0.116\right)$ and more importantly, a marginal time-by-group interaction (working memory: $F(1,31)=3.889, p=0.058, \eta_{\mathrm{p}}{ }^{2}=0.111$; inhibition: $F$ $\left.(1,31)=3.230, p=0.082, \eta_{\mathrm{p}}{ }^{2}=0.094\right)$. As regards working memory, parents of the intervention group rated their children as presenting less working memory difficulties after the intervention than before $(t(15)=2.894$, $p=0.011)$ which was not the case for the waiting-list group $(t(16)=0.275$, $p=0.787$ ) (see Figure 2). Regarding inhibition, the intervention group tended to reduce their inhibition difficulties, but this improvement did not reach statistical significance $(t(15)=1.931, p=0.073)$. In the waiting-list group, there was no change at all $(t(16)=-0.211, p=0.836)$ (see Figure 2 ).

Parents of children from the intervention group filled out the CHEXI again 4 months after the post-test. Paired samples $t$-test between post-test and follow-up ratings showed that the improvements still holds 4 months after the intervention (working memory: $t(13)=-0.589, p=0.566$; inhibition: $t(13)=-1.561, p=0.143$ ) (see Figures 2 and 3). 
Citation: Volckaert AMS, Noël MP (2016) Externalizing Behavior Problems in Preschoolers: Impact of an Inhibition Training. J Psychol Abnorm 5: 154 doi: 10.4172/2471-9900.1000154

Page 7 of 11

Behavior: Concerning the questionnaires (CPRS, CBCL), the repeated measures ANOVAs calculated for the Conners Parent Rating Scale showed a significant effect of time $(F(1,31)=21.167, p=<0.001$, $\left.\eta_{\mathrm{p}}^{2}=0.406\right)$ for the conduct problems scale, but no effect of group or timeby-group interaction (see Table 4$)$. Indeed, children globally reduced their conduct problems from pre- (mean $(\mathrm{SD})=63.70(13.62))$ to posttest $($ mean $(\mathrm{SD})=55.94(13.12))$. For the hyperactivity and impulsivity scales, respectively, we found a significant and marginal effect of time (hyperactivity: $F(1,31)=14.612, p=0.001, \eta_{p}^{2}=0.320 ;$ impulsivity: $F$ $\left.(1,31)=3.642, p=0.066, \eta_{\mathrm{p}}{ }^{2}=0.120\right)$ and more importantly a marginal time-by-group interaction (hyperactivity: $F(1,31)=3.783, p=0.061$, $\eta_{\mathrm{p}}{ }^{2}=0.109$; impulsivity: $\left.F(1,31)=3.188, p=0.084, \eta_{\mathrm{p}}{ }^{2}=0.093\right)$. Indeed, children from the waiting list were rated by their parents as equally hyperactive and impulsive in the pre- and post-test (hyperactivity: $t$ $(16)=1.339, p=0.199$; impulsivity: $t(16)=0.086, p=0.932)$ whereas, in the intervention group, parents rated their children as less hyperactive and less impulsive in the post-test than in the pretest (hyperactivity: $t$ $(15)=4.049, p=0.001$; impulsivity: $t(15)=2.641, p=0.019)$ (see Figures 4 and 5). Again, parents of children from the intervention group filled out the Conners Parent Rating Scale 4 months after the post-test. Paired samples $t$-test between post-test and follow-up ratings showed

\begin{tabular}{|c|c|c|c|c|c|}
\hline \multirow{3}{*}{ Variables } & & & \multicolumn{3}{|c|}{ Analysis (F) } \\
\hline & & \multirow[t]{2}{*}{$\mathbf{N}$} & $\begin{array}{c}\text { Main Effect of } \\
\text { Time }\end{array}$ & $\begin{array}{l}\text { Main } \\
\text { Effect of } \\
\text { Group }\end{array}$ & $\begin{array}{c}\text { Group } \\
\text { by time } \\
\text { interaction }\end{array}$ \\
\hline & & & $\left(n_{p}^{2}\right)$ & $\left(n_{p}^{2}\right)$ & $\left(n_{p}^{2}\right)$ \\
\hline Cognitive & Inhibition Factor & 31 & $22.196^{\star * *}(0.434)$ & 1.009 & 0.962 \\
\hline \multirow[t]{5}{*}{ measures } & Attention Factor & 32 & $10.398^{* \star}(0.257)$ & 0.547 & $\begin{array}{c}17.447^{\star \star \star} \\
(0.368)\end{array}$ \\
\hline & WM Factor & 34 & $13.443^{* * *}(0.296)$ & 0.593 & $\begin{array}{l}6.661^{* *} \\
(0.172)\end{array}$ \\
\hline & Flexibility & 34 & 1.916 & $\begin{array}{l}3.830^{\dagger} \\
(0.107)\end{array}$ & 0.05 \\
\hline & CHEXI WM (parent) & 33 & $5.480^{*}(0.150)$ & $\begin{array}{l}3.306^{\dagger} \\
(.096)\end{array}$ & $\begin{array}{l}3.889^{\dagger} \\
(0.111)\end{array}$ \\
\hline & $\begin{array}{l}\text { CHEXI Inhibition } \\
\text { (parent) }\end{array}$ & 33 & 2.498 & $\begin{array}{l}4.080^{\dagger} \\
(.116)\end{array}$ & $\begin{array}{l}3.230^{\dagger} \\
(0.094)\end{array}$ \\
\hline Behavioral & $\begin{array}{l}\text { UCG positive } \\
\text { affects }\end{array}$ & 32 & $3.224^{\dagger}(0.097)$ & 1.09 & 0.027 \\
\hline \multirow[t]{10}{*}{ measures } & $\begin{array}{l}\text { UCG negative } \\
\text { affects }\end{array}$ & 32 & 0.802 & 0.056 & $\begin{array}{l}4.366^{*} \\
(0.127)\end{array}$ \\
\hline & UCG agitation & 32 & 0.617 & $\begin{array}{l}6.286^{*} \\
(0.173)\end{array}$ & $\begin{array}{l}9.870^{* *} \\
(0.248)\end{array}$ \\
\hline & UCG inattention & 32 & 1.752 & 0.488 & 0.052 \\
\hline & $\begin{array}{l}\text { CPRS conduct } \\
\text { problems }\end{array}$ & 33 & $21.167^{\star * *}(0.406)$ & 0.709 & 0.032 \\
\hline & CPRS hyperactivity & 33 & $14.612^{* * *}(0.320)$ & 1.853 & $\begin{array}{l}3.783^{\dagger} \\
(0.109)\end{array}$ \\
\hline & CPRS impulsivity & 33 & $3.642^{\dagger}(0.105)$ & 1.259 & $\begin{array}{l}3.188^{\dagger} \\
(0.093)\end{array}$ \\
\hline & CBCL Anx/Dep & 34 & $16.729^{\star * *}(0.343)$ & 2.169 & 1.859 \\
\hline & CBCL Att Prob & 34 & 1.643 & 0.207 & 2.507 \\
\hline & CBCL Agg Behav & 34 & $31.672^{* * *}(0.497)$ & $\begin{array}{l}3.832^{\dagger} \\
(0.107)\end{array}$ & $\begin{array}{l}8.019^{* *} \\
(0.200)\end{array}$ \\
\hline & CBCL EB & 34 & $24.079^{* * *}(0.429)$ & $\begin{array}{l}2.926^{\dagger} \\
(0.084)\end{array}$ & $\begin{array}{l}7.953^{* *} \\
(0.199)\end{array}$ \\
\hline
\end{tabular}

Note: WM=Working memory; $\mathrm{CHEXI}=$ Childhood Executive Functioning Inventory; UCG=Unfair Card Game; CPRS=Conners Parent Rating Scale; CBCL Anx/Dep: Anxiety/Depression scale of the CBCL; CBCL Att Prob : Attention problems scale of the CBCL; CBCL Agg Behav: Aggressive Behaviors scale of the CBCL; CBCL $E B=$ Externalized Behaviors scale of the $C B C L ; n p^{2}=$ Partial eta squares (effect size) † $p \leq 0.10{ }^{*} p \leq 0.05,{ }^{* *} p \leq 0.01,{ }^{* * *} p<0.001$

Table 4: Results of repeated measure ANOVAs for cognitive and behavioural measures with the two groups (training and waiting-list groups).

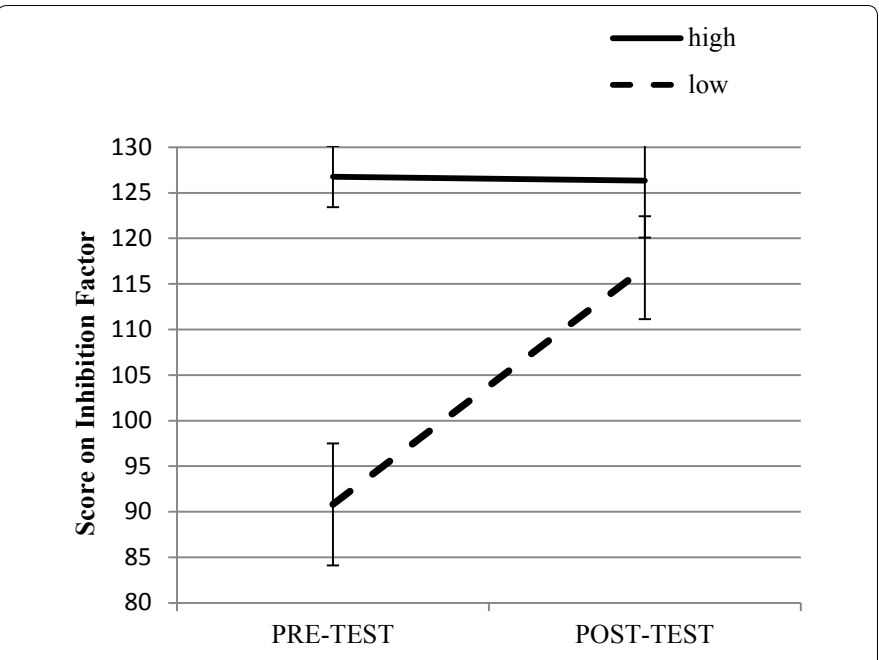

Figure 1: Level of inhibition in pre- and post-test for the intervention group, split with respect to inhibition level in pretest (+ standard error).

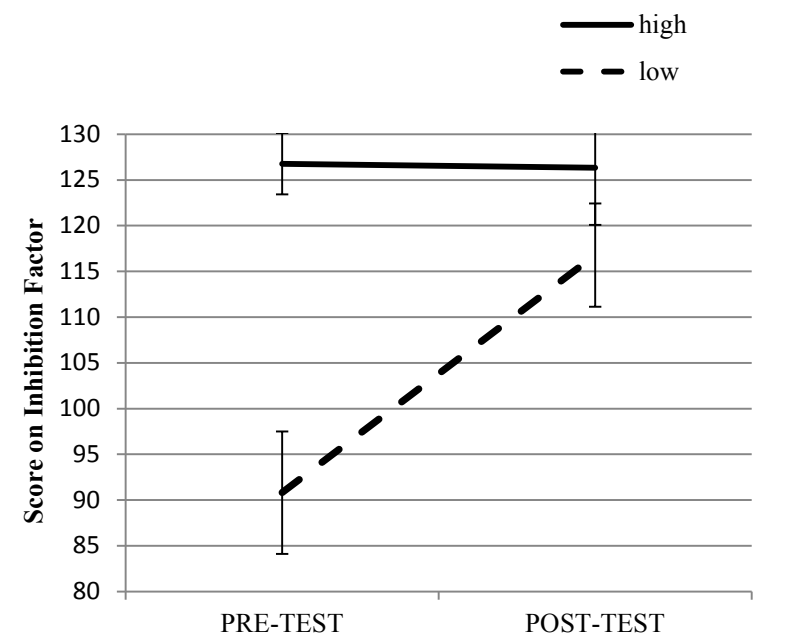

Figure 2: Level of WM difficulties rated by parents with CHEXI in pre and posttest for intervention and waiting-list groups (+ standard error).

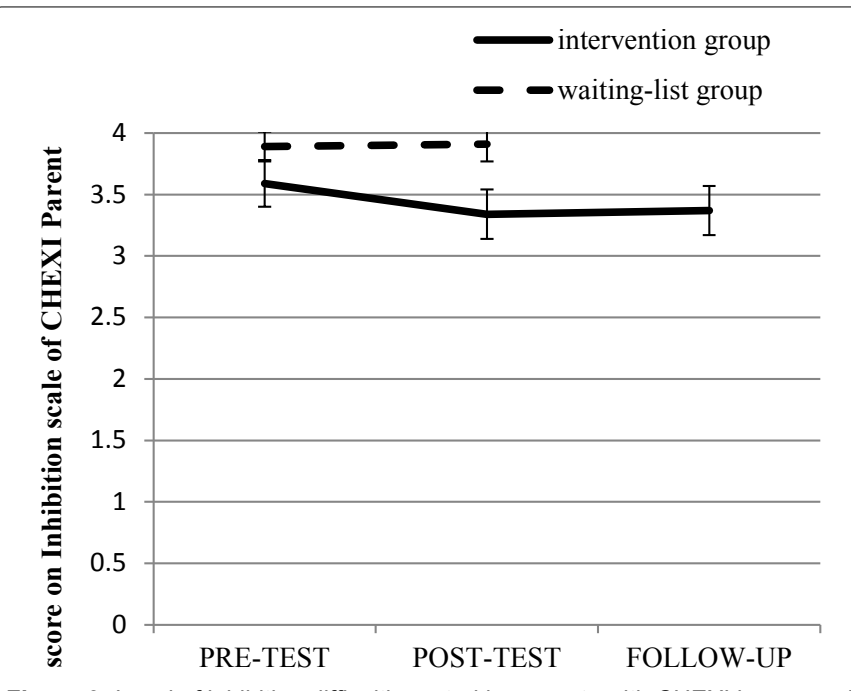

Figure 3: Level of inhibition difficulties rated by parents with $\mathrm{CHEXI}$ in pre- and post-test for intervention and waiting-list groups (+ standard error). 
Citation: Volckaert AMS, Noël MP (2016) Externalizing Behavior Problems in Preschoolers: Impact of an Inhibition Training. J Psychol Abnorm 5: 154. doi: 10.4172/2471-9900.1000154

Page 8 of 11

that the improvement on the hyperactivity and impulsivity scale still holds 4 months after the intervention (hyperactivity: $t(13)=-1.611$, $p=0.131$; impulsivity: $t(13)=-1.204, p=0.250)$.

For the CBCL, the repeated measures ANOVAs calculated on the $E B$ scale showed a significant effect of time $(F(1,32)=24.079, p<0.001$, $\left.\eta_{\mathrm{p}}{ }^{2}=0.429\right)$ and a marginal effect of group $(F(1,32)=2.926, p=0.097$, $\left.\eta_{\mathrm{p}}=0.084\right)$ qualified by a significant time-by-group interaction $(F$ $\left.(1,32)=7.953, p=0.008, \eta_{p}{ }^{2}=0.199\right)$ (see Figure 6). Indeed, parents rated their children as presenting less EB problems after the intervention than before $(t(16)=4.690, p<0.001)$ which was not the case for the waiting-list group $(t(16)=1.840, p=0.084)$. This training effect observed on the EB scale is in fact due to the Aggressive Behavior scale more than to the Attention Problem scale. Indeed, a significant effect of time $\left(F(1,32)=31.672, p<0.001, \eta_{\mathrm{p}}{ }^{2}=0.497\right)$, a marginal effect of group $\left(F(1,32)=3.832, p=0.059, \eta_{\mathrm{p}}{ }^{2}=0.107\right)$ and a significant time-by-group interaction $\left(F(1,32)=8.019, p=0.008, \eta_{\mathrm{p}}^{2}=0.200\right)$ is observed for the

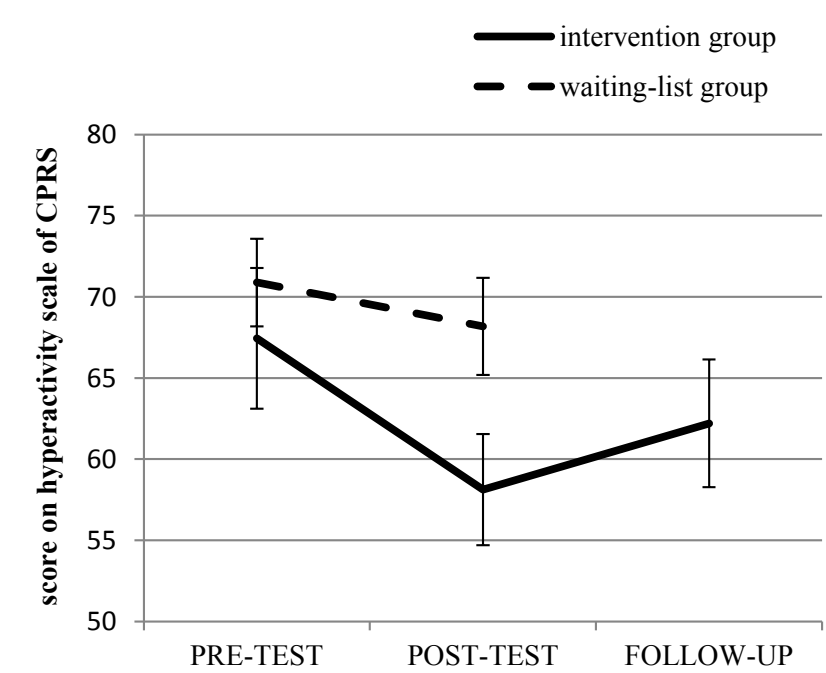

Figure 4: Level of hyperactivity symptoms rated by parents in CPRS in pre- and post-test for intervention and waiting-list groups (+ standard error).

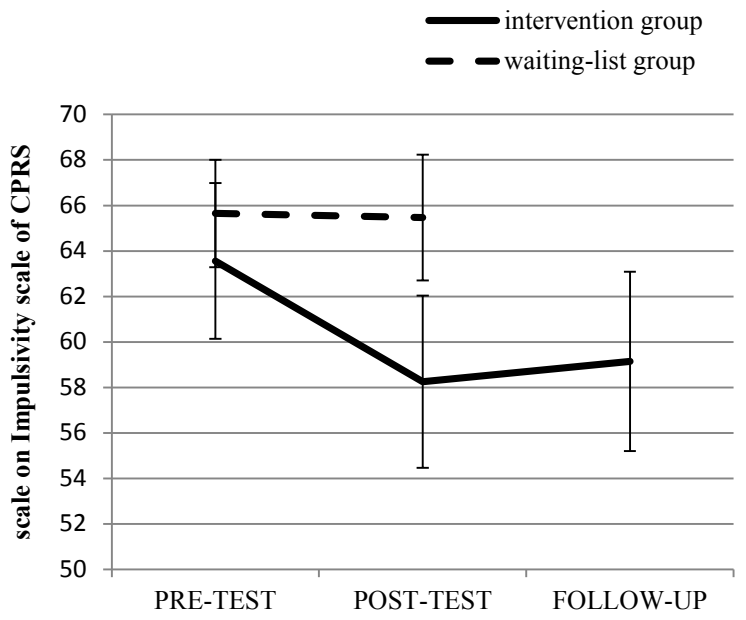

Figure 5: Level of impulsivity symptoms rated by parents in CPRS in pre- and post-test for intervention and waiting-list groups (+ standard error).

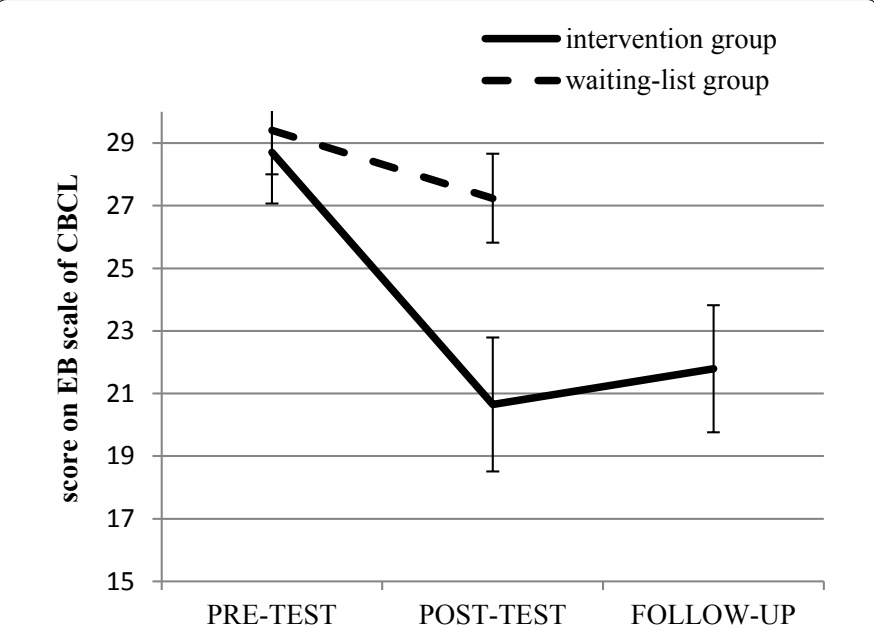

Figure 6: Level of EB symptoms rated by parents in $C B C L$ in pre- and post-test for intervention and waiting-list groups (+ standard error).

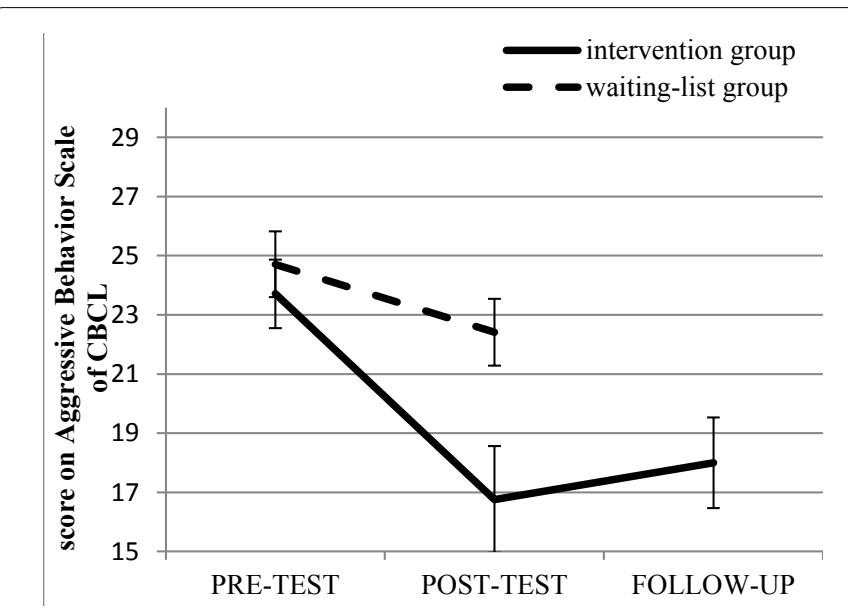

Figure 7: Level of aggressive behaviors rated by parents in $\mathrm{CBCL}$ in pre- and post-test for intervention and waiting-list groups (+ standard error).

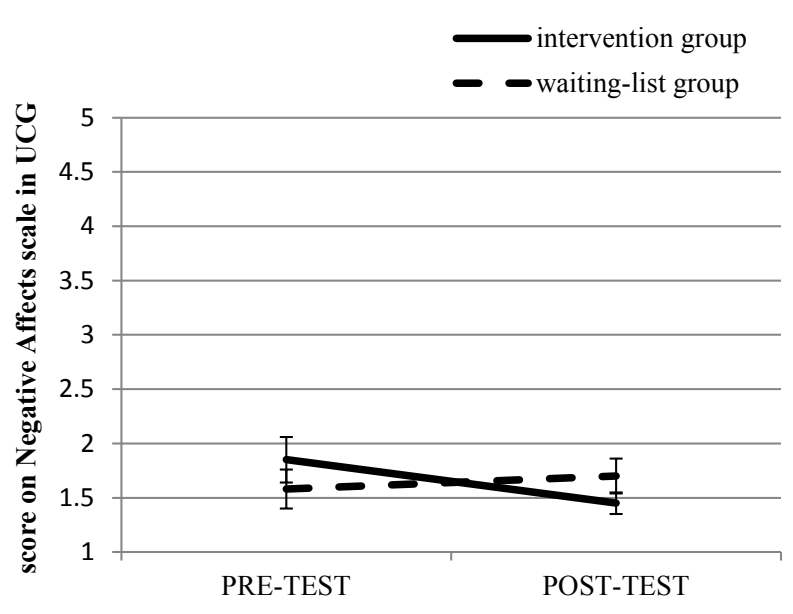

Figure 8: Level of negative affects observed in UCG in pre- and post-test for intervention and waiting-list groups (+ standard error). 


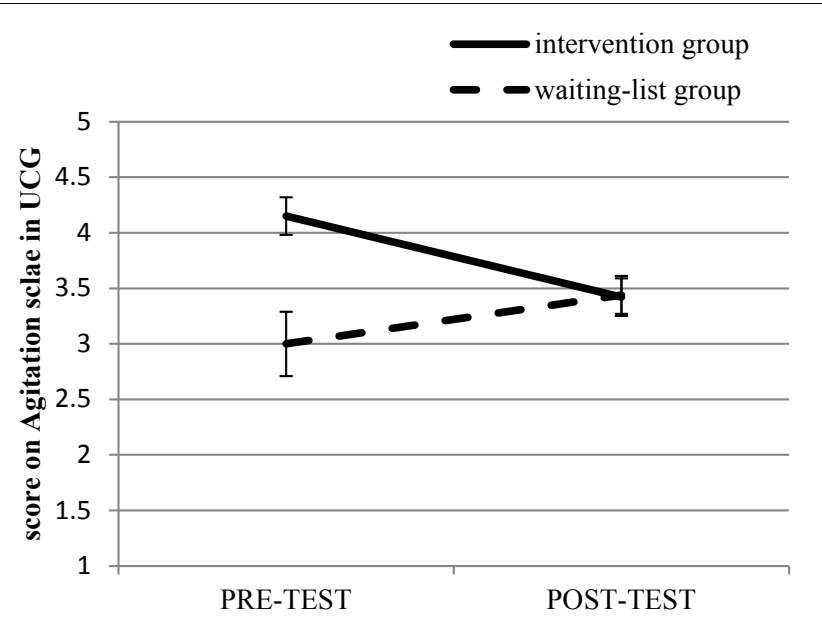

Figure 9: Level of agitation observed in UCG in pre- and post-test for intervention and waiting-list groups (+ standard error).

Aggressive Behavior scale (see Figure 7) but no effect at all for the Attention Problem scale. We have not observed either any effect on the Anxiety/Depression scale, and this seems relevant. Indeed, our intervention specifically targeted the improvement of EB, not the more general well-being of the child which includes also internalizing behaviors.

Finally, paired samples $t$-test between post-test and follow-up ratings showed that the improvement on the $E B$ and Aggressive behavior scales still holds 4 months after the intervention (EB: $t(13)=-$ 1.395, $p=0.187$; Aggressive behavior: $t(13)=-1.406, p=0.183$ ).

Finally, ANOVAs calculated on the four dimensions of our observational paradigm, the UCG, showed a significant time-by-group interaction for negative effects $\left(F(1,30)=4.366, p=0.045, \eta_{p}^{2}=0.127\right)$ and for agitation $\left(F(1,30)=6.286, p=0.004, \eta_{p}{ }^{2}=0.173\right)$ (see Table 4). Indeed, children from the intervention group showed a decrease of their negative effects and agitation in the posttest, whereas the opposite was true for the waiting-list group (see Figures 8 and 9). No significant time-by-group interaction was found for positive affects or inattention.

Gender effect: Developmental research often shows gender effects for externalizing behaviors. The link between executive functions and EB would be stronger in sample including a greater proportion of boys [32]. In this study, we did not find any gender effect: boys and girls have benefited equally from the intervention, either on cognitive or behavioral variables.

\section{Discussion}

In this research, we wanted to test the causal link between EF and EB by implementing an intervention in EB preschoolers focusing specifically on inhibition and then observing the possible impact on EB. To that end, we replicated with EB preschoolers, the intervention of Volckaert and Noël [39] who showed, in TD preschoolers, the effectiveness of an inhibition training on executive functions but also on external behavior.

By thoroughly replicating this study in a clinical population, we wanted to test whether this intervention would lead to the same beneficial effects with EB preschoolers and compare them to EB preschoolers who were on a waiting list. We had two hypotheses concerning our potential results. First, as Volckaert and Noël [39] showed that children with a low inhibition level in pretest were the ones who benefited more from the inhibition training, we might have expected that children with $\mathrm{EB}$, who are characterized by EF difficulties, would largely benefit from that intervention. Accordingly, the intervention would lead to both an EF improvement and a decrease of their EB problems. A second (and contrary) hypothesis was that, as EB preschoolers have multiple risk factors [15,16], focusing only on inhibition would not lead to a significant improvement in EF and EB. We thus decided in this research to compare the progress of the EB children in the training and waiting list conditions for both their EF capacities and their EB problems.

As Volckaert and Noël [39] showed a tendency to improve inhibition capacities after the intervention, we expected that our results would point in the same direction. However, despite the fact that we observe a significant effect of time indicating that children improved in inhibition tasks from pre- to post-test, we did not find any time-by-group interaction. Yet, as these authors did, we found that children who had a low level of inhibition in pretest were those who benefitted most from the intervention, whereas children who began the intervention with a high level of inhibition (although having no ceiling performance) did not show any improvement. This may confirm the hypothesis of Volckaert and Noël [39] suggesting that, as the intervention is led by groups of four children but the groups are not constituted on the basis of inhibition level at pretest, maybe some of the children in the group are not challenged enough in their proximal zone of development with these exercises. Concerning the transfer to other EF, we wanted to observe the effect of the intervention on attention, working memory and flexibility. In their study, Volckaert and Noël [39] observed an improvement from pre- to post-test on both attention and working memory capacities only for their experimental group, proving the benefit for other EF of the intervention focusing on inhibition. Surprisingly, we did not observe the same results in this present study. Instead, the waiting-list group actually seemed to improve their attention and working memory capacities more than children in the intervention group. Justifying these surprising results remains difficult. Concerning attention, we may note that the two groups differed in pretest, with a lower level for the waiting-list group than the intervention group, perhaps allowing them a bigger possibility of improvement. Note however that, in this study, we added an EF questionnaire (CHEXI) allowing us to have parental evaluation of EF. Despite the fact that we did not observe any improvement on working memory tasks, parents of children who received the intervention rated their child as presenting less working memory difficulties after the training. The same tendency also appears for their rating of inhibition. Finally, we found that, like Volckaert and Noël [39] and Tamm, Nakonezny and Hughes [38], we did not find any effect of the intervention on flexibility, confirming the idea that, as flexibility capacities are still at the beginning of their development at this very young age, it is difficult to observe an improvement for this EF.

As we used exactly the same intervention program as in Volckaert and Noël [39], we expected to observe the same positive results for cognitive variables. The failure to find a significant improvement in the cognitive tasks in this present study could possibly be due to the fact that, maybe, more training sessions would have been necessary to induce a significant change in cognitive capacities in EB population. Another possibility would have been to involve the parents (as in Tamm et al. [38]) in understanding the role of EF in everyday life activities and using the metacognitive tools (the policeman, the statue and the detective) to help their children exert their behavioral control at home as well. However, two observations are worth nothing here. First, although no significant improvement was measured in the 
cognitive tasks, parents rated their children as presenting less working memory difficulties and a tendency for less inhibition problems after the training. Second, a significant improvement of inhibition capacities was indeed observed in those children who had lower inhibition skills to start with. Hence, the children of this study were not selected on the basis of EF difficulties but according to their EB level. Even if we know that EF difficulties are a risk factor for developing EB, we know that all children with EB do not present weak EF functions [58]. Possible future studies might consider running the same program but only on children with EB and associated poor EF.

Concerning the behavioral measures, improvements in parental evaluations were highlighted. Indeed, parents rated their child as less impulsive after the intervention, and as presenting less EB, specifically fewer aggressive behaviors. One could posit that these improvements in parental evaluation for the intervention group were due to the fact that parents knew that their child was participating in the training. However, these results are specific as no such improvement was reported by the parents regarding anxiety and depression. Second, these parental ratings were confirmed with our observational paradigm, which is a more objective measure, allowing us to exclude a possible placebo effect. Indeed, as in Volckaert and Noël [39], we also observe a decrease of negative reactions and of agitation symptoms in UCG. Here, it is important to note that the coder for UCG was a trained coder not implicated in this research, blind to the group in which children belonged to. So we can exclude any possible bias relative to the experimenter's expectations.

The more important result in this study is the observation of a significant reduction of $\mathrm{EB}$ problems in those children after the training. This reduction was larger than the one observed in the waiting-list group and it remained stable 4 months after the end of the intervention. It was reported by parents through questionnaires but it was also measured in an observational paradigm. Furthermore, this reduction was even stronger than the one reported previously by Volckaert and Noël [39] on TD children. This last positive outcome might of course be due to the fact that by definition, EB children present more problematic behavior than TD children which leaves more space to improvement. Yet, even in the TD population, floor effects were not present at the post-test and thus there was room for a larger improvement. In sum, taking care of the children in small groups and playing games that allow them to become aware of their cognitive control processes (though the three characters) and use them in games lead to significant improvement of their EB.

Further studies might consider possible benefits of this intervention on social cognition as well. Indeed, for instance, in playing the detective, the child learns to be in another child's shoes. Possibly, some form of empathy could develop through this type of practice. Also, playing cooperation games could increase cooperation skills in children. Finally, as children improve their inhibition abilities, they might become more able to inhibit their own perspective and take into account others' perspective.

We need to point out some limitations in this study. First, children from this study are considered as presenting EB on the basis of parental evaluation, and not because they have been diagnosed by a clinician. An objective evaluation of EB as an inclusion criterion would have been useful to ensure that the difficult behaviors reported by parents really represented EB. We asked teachers to fill out the Conners questionnaire in order to have another external informant, but too few teachers accepted for us to use those data.

Second, as the waiting-list group received some other type of intervention after their own post-test for obvious ethical reasons (we could not ask parents to wait for 8 weeks without offering their EB child any intervention after the post-test), they did not participate in the 4 months follow-up. It was then difficult to correctly analyze these follow-up data, at least for cognitive variables, as we could not control the possible spontaneous development of the children, given that preschool age is a critical period for the emergence of EF. Nevertheless, we observe that the positive change in parental rating of $\mathrm{EB}$, aggressive behaviors, hyperactivity and impulsivity in post-test for the intervention group still holds four months after the intervention. This is thus very promising.

In conclusion, this present study was carried out to test whether the inhibition intervention used by Volckaert and Noël [39] on TD children could also have a positive impact on an EB population. Results showed that, even if the impact is not the same on cognitive variables, we observed a positive change in parental evaluation that lasts four months after and that is also observed in our observational paradigm.

\section{Acknowledgement}

This project was financially supported by a concerted research action on externalizing behavior (Convention ARC 11/16-038). Pr. Marie-Pascale Noël is also supported by the National Research Fund of Belgium. The authors wish to thank the families for collaborating on this project. We also thank our many sponsors for all the gifts we have been able to offer to our participants (Alice Délice, Martin's Spa, Tao, Libris Agora, Musée Hergé, Musée de Louvain-la-Neuve, Promosport, Bayard Milan). Finally, the authors also thank the reviewers for their comments and suggestions.

\section{References}

1. Smeekens S, Walraven JR, van Bakel H (2007) Multiple determinants of externalizing behavior in 5 year olds: A longitudinal model. Journal of Abnormal Child Psychology 35: 347-361.

2. Achenbach TM, Edelbrock CS (1986) Manual for teacher version of the child behav-ior checklist and child behavior profile. University of Vermont Department of Psychiatry Burlington.

3. Association AP (2003) Diagnostic and statistical manual of mental disorders DSM-5. American Psychiatric Association.

4. Palfrey JS (1985) The emergence of attention deficit in early childhood : A prospective study. Journal of Developmental and Behavioral Pediatrics 6: 339-348.

5. Richman N, Stevenson J, Graham P (1982) Pre-school to school: A behavioura stud. London: Academic Press.

6. Wakschlag LS (2007) A developmental framework for distinguishing disruptive behavior from normative misbehavior in preschool children. Journal of Child Psychology and Psychiatry 48: 976-987.

7. Campbell SB (1994) Hard-to-manage preschool boys: Externalizing behavior social competence and family context at two-year followup. Journal of abnormal child psychology 22: 147-166.

8. Campbell SB (2002) Behavior problems in preschool children. (2nd edn) New York: Guilford Press.

9. Moffit TE (1993) The neuropsychology of conduct disorder. Development and Psychopathology 5: 135-151.

10. Owens EB, Shaw DS (2003) Predicting growth curves of externalizing behavior across the preschool years. Journal of Abnormal Child Psychology 31: 575-590.

11. Reef J (2011) Developmental trajectories of child to adolescent externalizing behavior and adult DSM-IV disorder: Results of a 24 year longitudinal study. Social Psychiatry and Psychiatric Epidemiology 46: 1233-1241.

12. Spira EG, Fischel JE (2005) The impact of preschool inattention, hyperactivity and impulsivity on social and academic development: A review. Journal of Child Psychology and Psychiatry 46: 755-773.

13. Hinshaw SP(1992) Externalizing behavior problems and academic underachievement in childhood and adolescence: Causal relationships and underlying mechanisms. Psychological Bulletin 111: 127-155.

14. Masten AS (2005) Developmental cascades: Linking academic achievement 
Citation: Volckaert AMS, Noël MP (2016) Externalizing Behavior Problems in Preschoolers: Impact of an Inhibition Training. J Psychol Abnorm 5: 154. doi: 10.4172/2471-9900.1000154

and externalizing and internalizing symptoms over 20 years. Developmental psychology 41: 733.

15. Deater-Deckard K (1998) Multiple risk factors in the development of externalizing behavior problems: Group and individual differences. Development and Psychopathology 10: 469-493.

16. Roskam I (2013) When there seem to be no predetermining factors: Early child and proximal family risk predicting externalizing behavior in young children incurring no distal family risk. Research in Developmental Disabilities 34: 627639.

17. Corapci F, Wachs TD (2002) Does parental mood or efficacy mediate the influence of environmental chaos upon parenting behavior? Merrill-Palmer Quarterly 48: 182-201.

18. Farbiash T (2014) Prediction of preschool aggression from DRD4 risk, parental ADHD symptoms and home chaos. Journal of Abnormal Child Psychology 42 489-499.

19. Guedeney A, Dugravier R (2006) Les facteurs de risque familiaux et environnementaux des troubles du comportement chez le jeune enfant: Une revue de la littérature scientifique anglo-saxonne. La psychiatrie de l'enfant 49: $227-278$.

20. Hughes C, Ensor R (2008) Does executive function matter for preschoolers problem behaviors? Journal of Abnormal Child Psychology 36: 1-14

21. Bohlin G (2012) Disorganized attachment and inhibitory capacity: Predicting externalizing problem behaviors. Journal of Abnormal Child Psychology 40: 449-458

22. Berlin L, Bohlin G, Rydell AM (2003) Relations between inhibition, executive functioning and ADHD symptoms: A longitudinal study from age 5 to $81 / 2$ years. Child Neuropsychology 9: 255-266.

23. Berwid OG (2005) Sustained attention and response inhibition in young children at risk for attention deficit/hyperactivity disorder. Journal of Child Psychology and Psychiatry 46: 1219-1229.

24. Brophy M, Taylor E, Hughes C (2002) To go or not to go: Inhibitory control in 'hard to manage' children. Infant and Child Development 11: 125-140.

25. Fahie CM, Symons DK (2003) Executive functioning and theory of mind in children clinically referred for attention and behavior problems. Journal of Applied Developmental Psychology 24: 51-73.

26. Raaijmakers MAJ (2008) Executive functions in preschool children with aggressive behavior: Impairments in inhibitory control. Journal of Abnorma Child Psychology 36: 1097-1107.

27. Mariani MA, Barkley RA (1997) Neuropsychological and academic functioning in preschool boys with attention deficit hyperactivity disorder. Developmental Neuropsychology 13: 111-129.

28. Hughes C, Dunn J, White A (1998) Trick or treat? Uneven understanding of mind and emotion and executive dysfunction in 'hard-to-manage' preschoolers. Journal of Child Psychology and Psychiatry and Allied Disciplines 39: 981-994.

29. Sonuga-Barke EJS (2002) Are planning, working memory and inhibition associated with individual differences in preschool ADHD symptoms? Developmental Neuropsychology 21: 255-272.

30. Youngwirth SD (2007) Neuropsychological abilities of preschool-aged children who display hyperactivity and/or oppositional-defiant behavior problems. Child Neuropsychology 13: 422-443.

31. Pauli-Pott U, Becker K (2011) Neuropsychological basic deficits in preschoolers at risk for ADHD: A meta-analysis. Clinical Psychology Review 31: 626-637.

32. Schoemaker K (2013) Executive functions in preschool children with externalizing behavior problems: A meta-analysis. Journal of abnormal child psychology 41: 457-471.

33. Röthlisberger M (2011) Improving executive functions in 5 and 6 year old Evaluation of a small group intervention in pre-kindergarten and kindergarten children. Infant and Child Development.

34. Dowsett SM, Livesey DJ (2000) The development of inhibitory control in preschool children: Effects of 'executive skills' training. Developmental Psychobiology 36: 161-174.

35. Diamond A (2007) The early years: Preschool program improves cognitive control. Science 318: 1387-1388.
36. Thorell LB (2009) Training and transfer effects of executive functions in preschool children. Developmental Science 12: 106-113.

37. Klingberg T (2005) Computerized training of working memory in children with ADHD - A randomized, controlled trial. Journal of the American Academy of Child and Adolescent Psychiatry 44: 177-186.

38. Tamm L, Nakonezny PA, Hughes CW (2012) An open trial of a metacognitive executive function training for young children with ADHD. Journal of Attention Disorders 18: 551-559.

39. Volckaert AMS, Noël MP (2015) Training executive function in preschoolers reduce externalizing behaviors. Trends in Neuroscience and Education 4: 3747.

40. Achenbach TM, Rescorla LA (2000) Manual for the ASEBA preschool forms and profiles.

41. Wechsler DE (2004) WPPSI-III: Manuel d'interprétation. Paris: Les Editions du Centre de Psychologie Appliquée

42. Goyette $\mathrm{CH}$, Conners CK, Ulrich RF (1978) Normative data on revised conners parent and teacher rating scales. Journal of Abnormal Child Psychology 6: 221 236

43. Catale C (2014) The conners parent rating scale: Psychometric properties in typically developing 4-to 12 year old Belgian French-speaking children. Revue Européenne de Psychologie Appliquée/European Review of Applied Psychology 64: 221-227.

44. Roskam I (2015) The unfair card game: A promising tool to assess externalizing behavior in preschoolers. Pratiques Psychologiques.

45. Bukowski HB, Samson D (2015) Can emotions affect level 1 visual perspectivetaking? Cognitive Neuroscience, in press.

46. Noël MP. Chat-Chien-Poisson. unpublished

47. Gerstadt CL, Hong YJ, Diamond A (1994) The relationship between cognition and action: Performance of children 312-7 years old on a stroop-like day-night test. Cognition 53: 129-153.

48. Bouillet $L$ (2012) Proposition d'épreuves contribuant au dépistage des Troubles Déficitaires de l'Attention avec Hyperactivité (TDAH). ANAE. Approche neuropsychologique des apprentissages chez l'enfant 120: 593-605.

49. Korkman M, KirkU, Kemp S(1998)NEPSY: A developmental neuropsychological assessment. Psychological Corporation.

50. Ponitz CC (2009) A structured observation of behavioral self-regulation and its contribution to kindergarten outcomes. Developmental psychology 45: 605.

51. Noël MP (2009) Counting on working memory when learning to count and to add: A preschool study. Developmental Psychology 45: 1630.

52. Corsi PM (1973) Human memory and the medial temporal region of the brain ProQuest Information \& Learning

53. Catale C (2013) French adaptation of the childhood executive functioning inventory (CHEXI). European Journal of Psychological Assessment 29: 149

54. Gagné PP, Longpré LP (2004) Apprendre avec Réflecto. Chenelière/McGraw Hill.

55. Lehto JE (2003) Dimensions of executive functioning: Evidence from children British Journal of Developmental Psychology 21: 59-80.

56. Miyake A (2000) The unity and diversity of executive functions and their contributions to complex "Frontal Lobe" tasks: A latent variable analysis. Cognitive Psychology 41: 49-100.

57. Miyake A, Friedman NP (2012) The nature and organization of individual differences in executive functions four general conclusions. Current Directions in Psychological Science 21: 8-14.

58. Volckaert AMS, Noël MP. Executive function, chaos and temperament: Specificities in preschoolers with externalizing behaviors. in preparation. 